\title{
Different indications, one procedure: Thyroidectomy (as simple as that)
}

\author{
Andra COCOLOS ${ }^{1}, \mathrm{MD}, \mathrm{PhD}$ student, Nicoleta DUMITRU ${ }^{1,2}, \mathrm{MD}, \mathrm{PhD}$ student, \\ Assist. Prof. Mara CARSOTE ${ }^{1,2}$, MD, PhD, Assist. Prof. Eugenia PETROVA ${ }^{1,2}$, MD, PhD, \\ Lecturer Ana VALEA ${ }^{3,4}, \mathrm{MD}$, PhD, Assoc. Prof. Adina GHEMIGIAN ${ }^{1,2}, \mathrm{MD}, \mathrm{PhD}$ \\ 1"C.I. Parhon" National Institute of Endocrinology, Bucharest \\ "Carol Davila" University of Medicine and Pharmacy, Bucharest \\ 3"I. Hatieganu" University of Medicine and Pharmacy, Cluj-Napoca \\ ${ }^{4}$ Clinical County Hospital, Cluj-Napoca
}

\begin{abstract}
Introduction. Thyroidectomy is currently a rather simple procedure with various indications, regardless total or subtotal/near total, based on conventional approach or modern like robotic (trans-axillary and axillobreast robotic). We aim to introduce a few scenarios in daily endocrine practice based on a pictorial essay. This is a cases series. Case 1 is a 59-year old female with recent subclinical thyrotoxicosis with an extremely large multinodular goitre who was confirmed benign by the pathological report was provided after. Case 2 is a 70-year old female who self detected through palpation a large left thyroid macronodule with suspected ultrasound features. However, she still delays thyroidectomy. Case 3 is a 51-year old female also with compressive symptoms due multinodular goitre and a dominant left lobe nodule who was referred to surgery. Case 4 is a 59-year female treated with thiamazole for 12 years presents a large multinodular goitre which was referred to surgery.

Conclusion. Different scenarios are ending with the idea of thyroidectomy from compressive local symptoms, to curative option for a potential malignancy etc.
\end{abstract}

Keywords: thyroidectomy, thyroid nodule, goitre

\section{INTRODUCTION}

Thyroidectomy is currently a rather simple procedure with various indications, regardless total or subtotal/near total type, based on conventional approach or modern like robotic (transaxillary and axillo-breast robotic) $(1,2)$. We aim to introduce a few scenarios in daily endocrine practice based on a pictorial essay. This is a cases series.

\section{CASES SERIES}

\section{Case presentation 1}

This is 59-year old non-smoker female coming from non-endemic area who was found 3 months ago with subclinical thyrotoxicosis and a small dose of daily thiamazole was offered to her (with negative Thyroid Stimulating Hormone Receptor Antibody assay). She has a his- 
tory of untreated hypercholesterolemia. She currently accuses local compressive symptoms. Thyroid assays under daily $5 \mathrm{mg}$ of thiamazole are within normal limits. Thyroid ultrasound showed a very large gland so an abdominal probe was used to provide the maximum diameters of lobes. Right lobe has 4.5 by 4.3 by 9.8 $\mathrm{cm}$ (Fig. 1). It associates multiple izo-echoic nodules, some with necrosis and also a tendency to conglomerate; lower part of the lobe has a nodule of 4 by 2.2 by $2.8 \mathrm{~cm}$ with irregular shape, and another of 2.9 by 2.2 by $2.3 \mathrm{~cm}$ (Fig. 1).
Left thyroid lobe has 3.93 by 5.06 by $6.88 \mathrm{~cm}$ with 3-4 nodules of maximum 4 by $2.8 \mathrm{~cm}$ with tracheal deviation and luminal reduction (Fig. 1). Thyroid scintigram performed with iodine ${ }^{131}$ radiotracer indicated a typical multinodular goitre with inhomogeneous uptake of the tracer (Fig. 1). Total thyroidectomy was done without surgical complications; pathological report confirmed benign follicular aspects and the patient was offered daily life long levothyroxine substitution under periodic check-up of serum TSH.
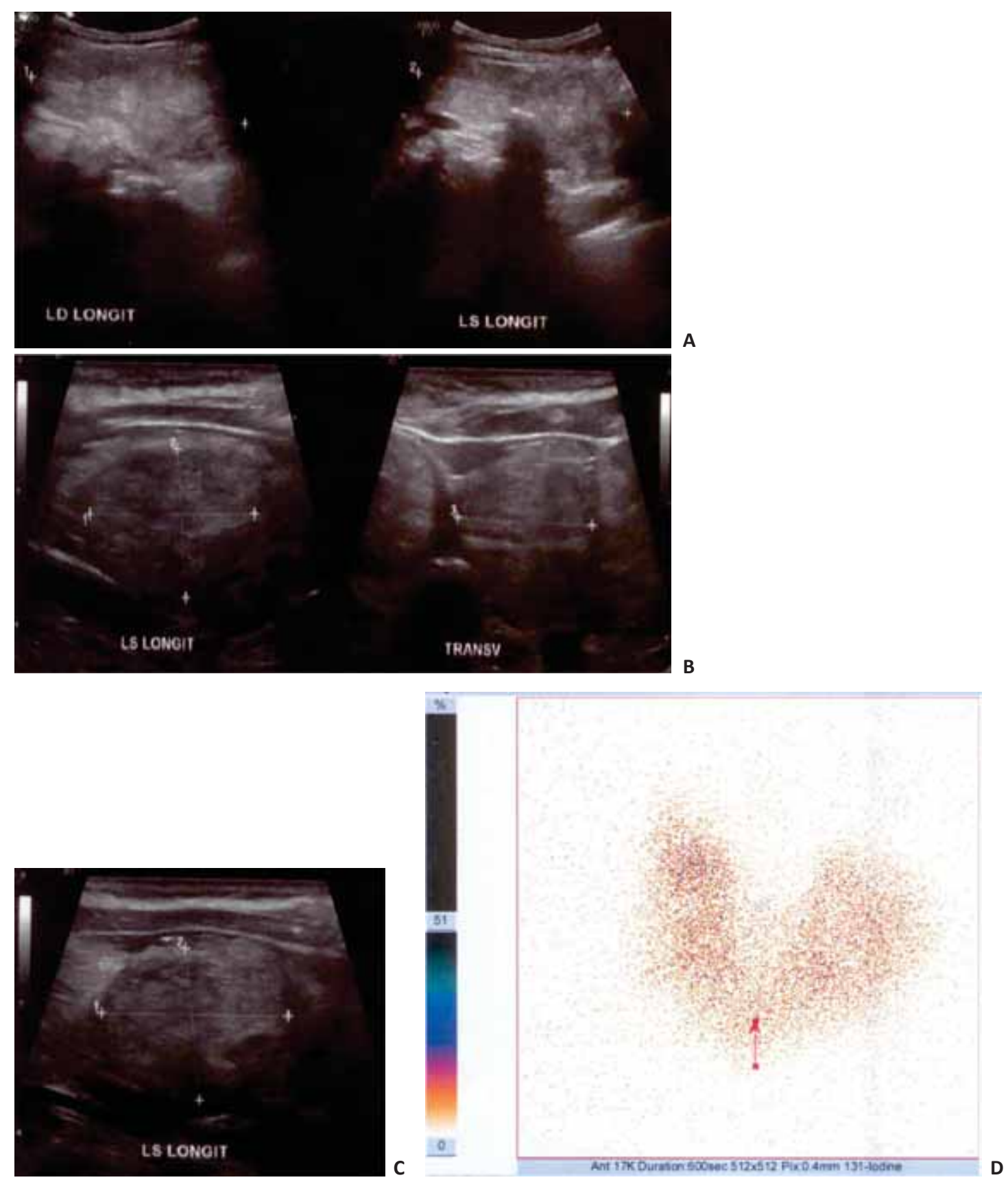

FIGURE 1. Thyroid ultrasound on a 59-year old female with right lobe has 4.5 by 4.3 by $9.8 \mathrm{~cm}(\mathrm{~A})$. It associates multiple izo-echoic nodules, some with necrosis and also a tendency to conglomerate; lower part of the lobe has a nodule of 4 by 2.2 by $2.8 \mathrm{~cm}$ with irregular shape, and another of 2.9 by 2.2 by $2.3 \mathrm{~cm}$. Left thyroid lobe has 3.93 by 5.06 by $6.88 \mathrm{~cm}$ (A) with 3-4 nodules (B) of maximum 4 by $2.8 \mathrm{~cm}$ (C) with tracheal deviation and luminal reduction. Thyroid scintigram performed with iodine ${ }^{131}$ radiotracer indicated a typical multi-nodular goitre with inhomogeneous uptake of the tracer (D). 


\section{Case presentation 2}

This is a 70-year old non-smoking female, known with B type chronic hepatitis, and lumbar spondylosis, who is admitted for accidental detection of a thyroid enlargement by self palpation. Her medical history regarding family is irrelevant. The subject comes from non-endemic area. Thyroid specific tests involving function, autoimmunity and neuroendocrine marker calcitonin are negative, as introduced in Table 1. Cervical ultrasound pointed a right thyroid lobe of 2.1 by 1.6 by $4.7 \mathrm{~cm}$ (centimetre), a left lobe of 1.2 by 1.3 by $>5.5 \mathrm{~cm}$ both displaying hypoechoic pattern. The left lobe is occupied at the lower part by a macronodule of 3.03 by 1.5 by $2.2 \mathrm{~cm}$ with hypoechoic pattern, and some microcalcifications and small areas of necrosis (Fig. 2). Right later cervical area does not associate any lymph nodes enlargement by the left part has lymph nodes of maximum 0.89 by 0.42 $\mathrm{cm}$. Surgery was recommended but the patient refused it, also the fine needle aspiration.

\section{Case presentation 3}

This is a 51-year old non-smoker female coming from non-endemic area. She is known

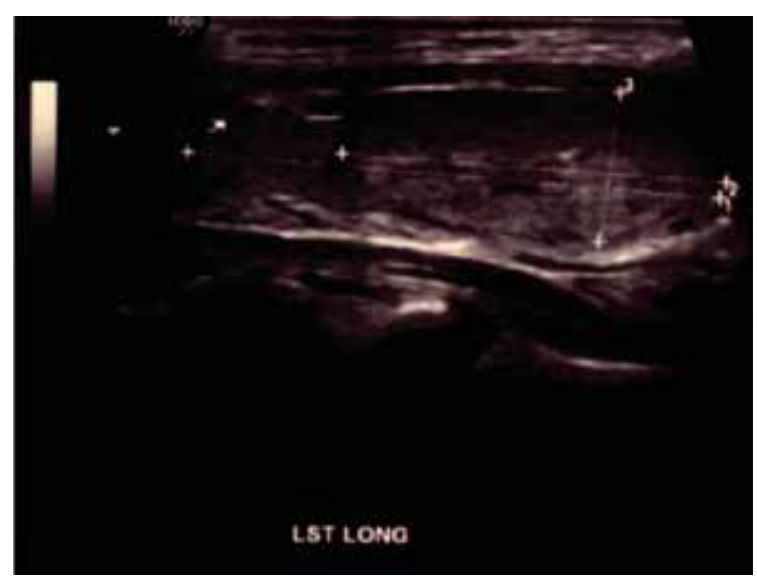

FIGURE 2. Left thyroid lobe with a macronodule on a 70-year old female (longitudinal plane) with high blood pressure and hypercholesterolemia. She progressively developed compressive cervical symptoms so she was admitted for thyroid evaluation. Normal thyroid function and antibodies against thyroid are detected. Ultrasound showed hypoechoic structure, a right lobe of 3.3 by 1.8 by $1.6 \mathrm{~cm}$, a left one of 3.16 by 2.321 by $1.8 \mathrm{~cm}$ with multiple nodules: of 1.1 by 1.1 by $1.03 \mathrm{~cm}$ (right lobe), of 0.6 by 0.6 by 0.5 $\mathrm{cm}$ (right lobe), of 2.78 by 2.07 by $1.94 \mathrm{~cm}$ with inhomogeneous pattern, poorly shaped, conglomerate-like features, displacing the left thyroid lobe (Fig. 3). No lymph nodes were detected at cervical ultrasound. Thyroidectomy is considered necessary.

\section{Case presentation 4}

This is a 59-year old female, known with chronic treatment for bipolar disorder, a subject who was treated for toxic goitre for the last 12 years. Mild local symptoms are described by the patient. Thyroid function is normalized under medication but an increased gland is detected at ultrasound: right lobe (of 4.7 by 2.4 by 2.06 $\mathrm{cm}$ ) with a well shaped nodule of 2.8 by 2.3 by $2.9 \mathrm{~cm}$ with increased vascularisation, and another of 1.3 by 1.1 by $1.4 \mathrm{~cm}$, and also another of 0.6 by 0.6 by $0.4 \mathrm{~cm}$, left lobe of 4.2 by 1.5 by $1.8 \mathrm{~cm}$ with multiple micro-nodules (maximum of 0.4 by $0.2 \mathrm{~cm}$ ) (Fig. 4). Total thyroidectomy was indicated and performed confirming benign features.

\section{DISCUSSION}

Large toxic goitre as seen in first case have indication of total thyroidectomy because of compressive symptoms, moreover the risk of gland increase during TSH rise which has a functional but also anatomical control of thyroid (3). The fourth case was referred to thyroidectomy because long time exposure to thiamazole, more than a decade in a situation when gland's

TABLE 1. The blood thyroid parameters in patients to whom indication of thyroidectomy has been established

\begin{tabular}{|l|c|c|c|c|}
\hline Case & $\begin{array}{c}\text { TSH } \\
\text { (Thyroid Stimulating } \\
\text { Hormone) }\end{array}$ & $\begin{array}{c}\text { FreeT4 } \\
\text { (Free levothyroxine) }\end{array}$ & $\begin{array}{c}\text { TPOAb } \\
\text { (thyroperoxidase } \\
\text { antibodies) }\end{array}$ & calcitonin \\
\hline $\mathbf{1}^{*}$ & 0.4 & 13.6 & 10 & 1 \\
\hline $\mathbf{2}$ & 0.363 & 13.3 & 31 & 1.96 \\
\hline $\mathbf{3}$ & 2.35 & 13.8 & 22.3 & 1.1 \\
\hline $\mathbf{4}^{*}$ & 0.343 & 13.1 & 10 & 1.4 \\
\hline units & $\mu \mathrm{UI} / \mathrm{ml}$ & $\mathrm{pmol} / \mathrm{l}$ & $\mathrm{Ul} / \mathrm{ml}$ & $\mathrm{ng} / \mathrm{ml}$ \\
\hline normal value & $0.5-4.5$ & $10.3-24.4$ & $0-35$ & $1-4.8$ \\
\hline
\end{tabular}

*under daily $5 \mathrm{mg}$ of thiamazole 
Practica Medicală - Vol. 13, Nr. 2(57), An 2018
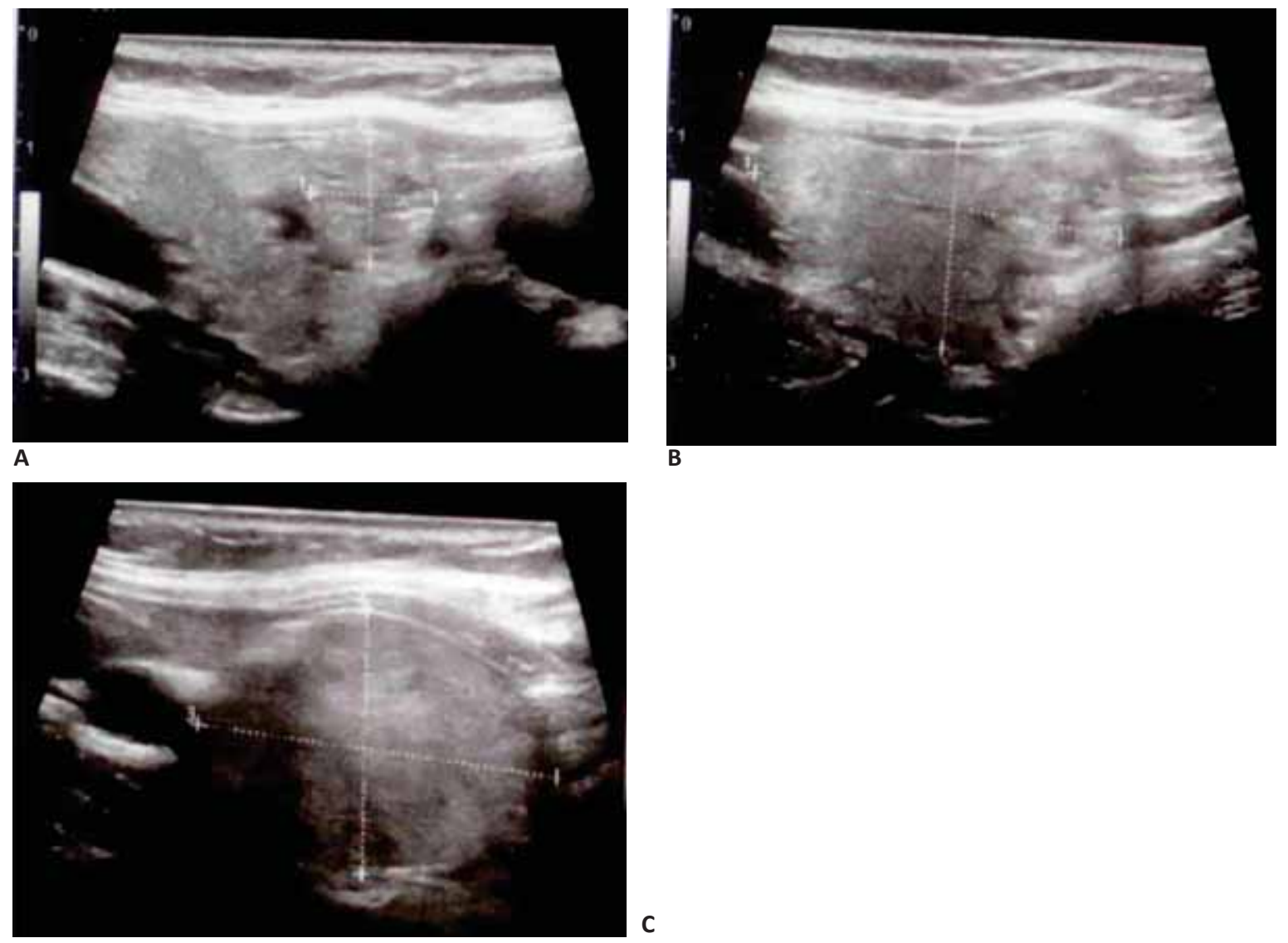

$\bar{B}$

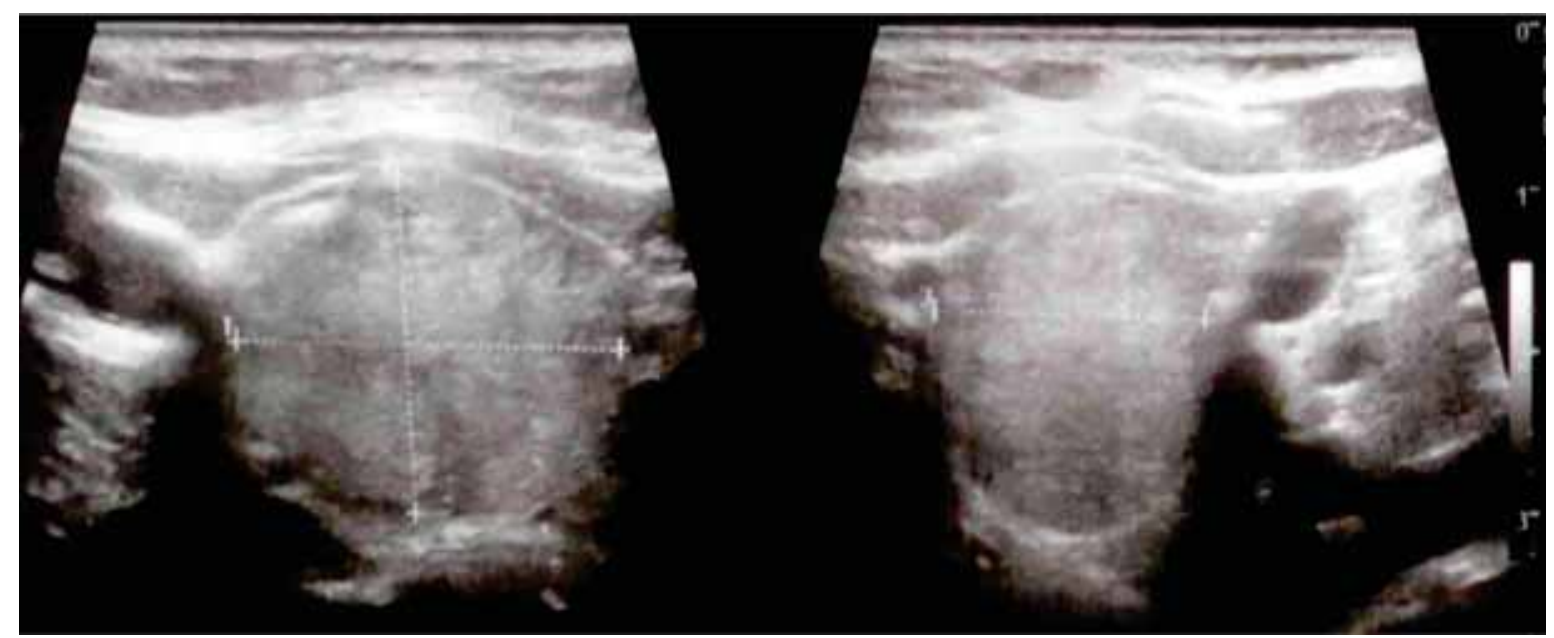

D

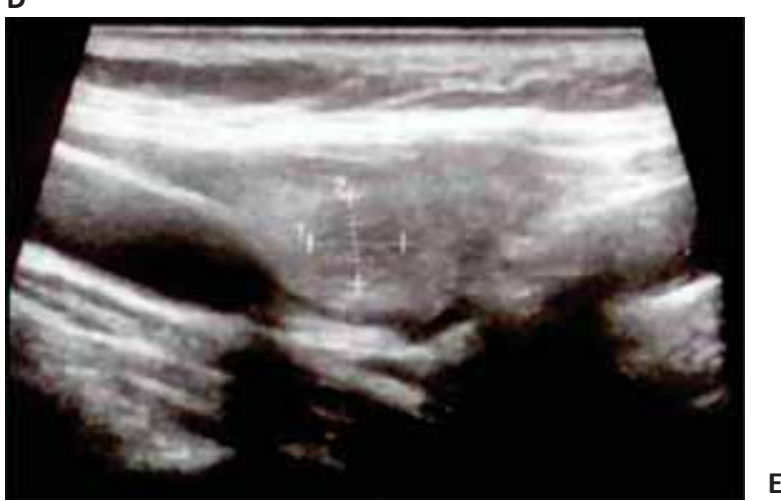

FIGURE 3. Ultrasound of the thyroid on a 51-year old female: hypoechoic structure, a right lobe of 3.3 by $1.8 \mathrm{by} 1.6 \mathrm{~cm}$ (B), a left one of 3.16 by 2.321 by $1.8 \mathrm{~cm}$ with multiple nodules: of 1.1 by 1.1 by $1.03 \mathrm{~cm}$ (right lobe) (A), of 0.6 by 0.6 by $0.5 \mathrm{~cm}$ (right lobe) (E), of 2.78 by 2.07 by $1.94 \mathrm{~cm}(D)$ with inhomogeneous pattern, poorly shaped, conglomerate-like features, displacing the left thyroid lobe 

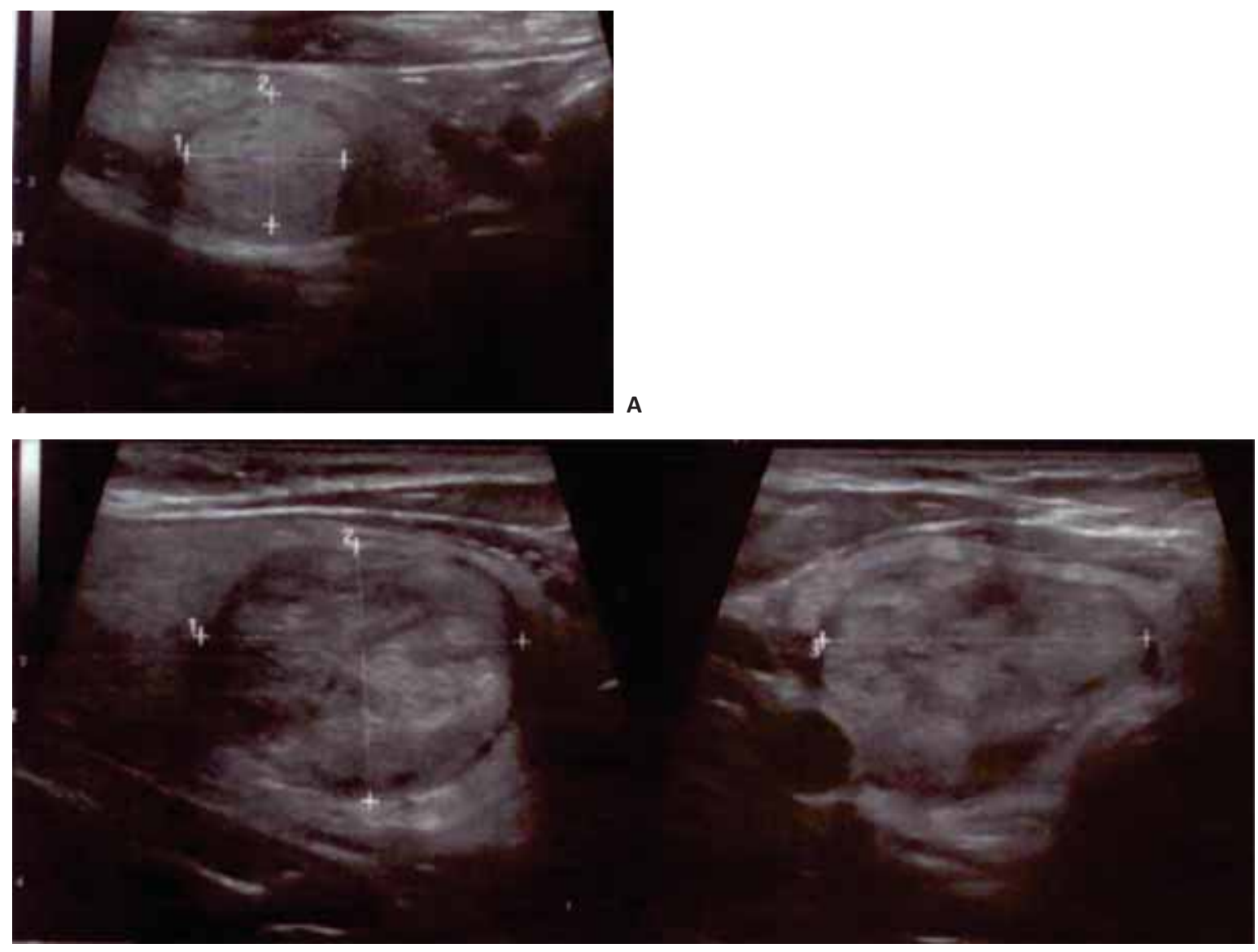

B

FIGURE 4. 59-year old female with a thyroid ultrasound showing a right lobe (of 4.7 by 2.4 by $2.06 \mathrm{~cm}$ ) with a well shaped nodule of 2.8 by 2.3 by $2.9 \mathrm{~cm}$ (B) with increased vascularisation, and another of 1.3 by 1.1 by $1.4 \mathrm{~cm},(A)$ and also another of 0.6 by 0.6 by $0.4 \mathrm{~cm}$, left lobe of 4.2 by 1.5 by $1.8 \mathrm{~cm}$ with multiple micronodules (maximum of 0.4 by 0.2 $\mathrm{cm})$

anatomy was not suitable for radioiodine ablative therapy (3).

The second and third case introduces the scenario of large thyroid with retrosternal development which does not allow precise assessment through neck ultrasound and it represents an indication for thyroid remove in addition to higher risk of malignancy pointed by ultrasound pattern of the nodule (4).

\section{CONCLUSION}

Different scenarios are ending with the idea of thyroidectomy from compressive local symptoms, radical decision after very long time exposure to thiamazole, to curative option for a potential malignancy etc.

\section{REFERNCES}

1. Dumitru N., Ghemigian A., Carsote M., Albu S.E., Terzea D., Valea A. Thyroid nodules after initial evaluation by primary health care practitioners: an ultrasound pictorial essay. Archives of the Balkan Medical Union (The Official Journal of the Balkan Medical Union, Fonded in 1963 as „Archives de L'Union Medicale Balcanique"). 2016;51(3):434-438.
2. Sun GH, Peress L, Pynnonen MA. Systematic review and meta-analysis of robotic vs conventional thyroidectomy approaches for thyroid disease. Otolaryngol Head Neck Surg. 2014 Apr;150(4):520-32.

3. Ross D.S., Burch H.B., Cooper D.S., Greenlee M.C., Laurberg P., Maia A.L., Rivkees S.A., Samuels M., Sosa J.A., Stan M.N., Walter M.A. 2016 American
Thyroid Association Guidelines for Diagnosis and Management of Hyperthyroidism and Other Causes of Thyrotoxicosis. Thyroid. 2016 Oct;26(10):1343-1421.

4. Burman K.D., Wartofsky L. Clinical Practice. Thyroid Nodules. N Engl J Med. 2015 Dec 10; 373(24):2347-56. 